\title{
HUBUNGAN PERSEPSI MASYARAKAT DENGAN KEPESERTAAN JKN MANDIRI DI WILAYAH KERJA PUSKESMAS PERAWATAN BAKAU TAHUN 2021
}

\author{
RELATIONSHIP COMMUNITY PERCEPTIONS WITH JKN MANDIRI \\ PARTICIPATION IN THE WORK AREA OF PUSKESMAS BAKAU IN 2021
}

\author{
Asrinawaty ${ }^{1^{*}}$, Mahmudah ${ }^{2}$ \\ 1,2Fakultas Kesehatan Masyarakat, Universitas Islam Kalimantan (UNISKA) MAB \\ Banjarmasin \\ Jl. Adhyaksa. No.2. Kota Banjarmasin, Kalimantan Selatan. Indonesia \\ *Email: rienfkm@gmail.com
}

\begin{abstract}
Strong, stable and sustainable health financing plays a very vital role for the implementation of health services in order to achieve various important goals of health development in a country, including equitable distribution of health services and access and quality services. This study aims to determine the perception of the community with independent JKN participation at the Mangrove Care Health Center in Kotabaru Regency in 2021. The research method is an analytic survey with a cross sectional approach. The population is all heads of families in the working area of the Mangrove Care Health Center in Kotabaru Regency in 2021 as many as 5,226 families. The sample is 98 respondents. Sampling using Random Sampling technique. Statistical test using Chi square test. The results showed that most of the participants did not become independent JKN participants as many as 58 people $(59.2 \%)$ positive perceptions of JKN as many as 64 people $(65.3 \%)$, received support from family as many as 83 people (84.7\%). There is a relationship between perceptions of JKN and independent JKN participation ( $p$-value $=0.000$ ) at the Mangrove Care Health Center in Kotabaru Regency in 2021. It is hoped that health workers can provide better facilities for the convenience of BPJS Health participants.
\end{abstract}

Keywords: Perception; JKN Mandiri Participant

\section{ABSTRAK}

Pembiayaan kesehatan yang kuat, stabil dan berkesinambungan memegang peranan yang amat vital untuk penyelenggaraan pelayanan kesehatan dalam rangka mencapai berbagai tujuan penting dari pembangunan kesehatan di suatu negara diantaranya adalah pemerataan pelayanan kesehatan dan akses serta pelayanan yang berkualitas. Penelitian bertujuan mengetahui persepsi masyarakat dengan kepesertaan JKN mandiri di Puskesmas Perawatan Bakau Kabupaten Kotabaru tahun 2021. Metode penelitian survey analitik dengan pendekatan cross sectional. Populasi adalah seluruh Kepala keluarga di wilayah kerja Puskesmas Perawatan Bakau Kabupaten Kotabaru tahun 2021 sebanyak 5.226 kepala keluarga. Sampel sebanyak 98 responden. Pengambilan sampel menggunakan teknik Random Sampling. Uji statistik menggunakan uji Chi square test. Hasil penelitian menunjukkan sebagian besar tidak menjadi peserta JKN mandiri sebanyak 58 orang $(59,2 \%)$ persepsi tentang JKN positif sebanyak 64 orang $(65,3 \%)$, mendapat dukungan dari keluarga sebanyak 83 orang $(84,7 \%)$. Ada hubungan persepsi tentang JKN dengan kepesertaan JKN mandiri $(\mathrm{p}-\mathrm{value}=0,000)$ di Puskesmas Perawatan Bakau Kabupaten Kotabaru tahun 2021. Diharapkan petugas kesehatan dapat menyedian fasilitas-fasilitas yang lebih baik lagi untuk kenyamanan peserta BPJS Kesehatan.

Kata kunci : Persepsi; Peserta JKN Mandiri 


\section{PENDAHULUAN}

Berdasarkan UU negara berkewajiban memberikan jaminan kesehatan kepada setiap penduduk agar mendapatkan akses pelayanan kesehatan dengan mutu yang terjamin dan memenuhi kebutuhan dasar kesehatan. Transformasi tersebut meliputi perubahan sifat, organ dan prinsip pengelolaan, atau dengan kata lain berkaitan dengan perubahan stuktur dan budaya organisasi. Selanjutnya, semua peserta jaminan kesehatan PT Askes akan dialihkan menjadi peserta jaminan kesehatan BPJS Kesehatan. Kepesertan BPJS meliputi peserta Penerima Bantuan Iuran (PBI), yang meliputi orang yang tergolong fakir miskin dan orang tidak mampu. Dan peserta Bukan PBI Jaminan Kesehatan,yaitu orang yang tidak tergolong fakir miskin dan orang tidak mampu yang terdiri atas:Pekerja Penerima Upah dan anggota keluarganya, Pekerja Bukan Penerima Upah dan anggota keluarganya;dan Bukan Pekerja dan anggota keluarganya (1).

Penelitian-penelitian terdahulu yang juga membahas tentang persepsi masyarakat tentang jaminan kesehatan seperti Eri Witcahyo (2016), tentang Kesiapan dan Persepsi Masyarakat Kabupaten Bondowoso terhadap Kebijakan Jaminan Kesehatan Nasional (JKN). Berdasarkan hasil penelitian dapat diketahui bahwa banyak masyarakat yang telah mendengar terkait JKN, namun informasi yang mereka dapatkan masih terbatas. Hal tersebut berdampak pada ketidakyakinan mereka untuk mengikuti JKN. Selain itu, penilaian terhadap prosedur kepesertaan JKN yang rumit juga menyebabkan masyarakat merasa enggan mengikuti jaminan kesehatan (2).

Pengumpulan data di Puskesmas Perawatan Bakau didapatkan bahwa target peserta JKN yaitu $100 \%$ dari jumlah penduduk sebanyak 16.651 orang namun capaian jumlah peserta JKN pada tahun 2020 sebanyak 2.067 orang adapun capaian JKN sampai April tahun 2021 sebanyak 2.246 orang (13,5\%) sehingga masih kurang dari target. Berdasarkan uraian diatas maka "Hubungan Persepsi Masyarakat dengan Kepesertaan JKN mandiri di Puskesmas Perawatan Bakau tahun 2021".

\section{BAHAN DAN METODE}

Metode penelitian yang digunakan adalah Survey analitik dengan pendekatan cross sectional. Populasi penelitian ini adalah seluruh Kepala keluarga di wilayah kerja Puskesmas Perawatan Bakau tahun 2021 sebanyak 5.226 dengan sampel dalam penelitian ini sebanyak 98 kepala keluarga. Ada pun teknik pengambilan sampel dalam penelitian ini dengan cara Random Sampling. Variabel yang digunakan dalam penelitian ini yaitu variabel bebas (variabel independen) adalah persepsi masyarakat tentang JKN dan Variabel terikat (dependen) dalam penelitian ini adalah kepesertaan JKN mandiri. Analisis data yang digunakan adalah analisis univariat dan analisis bivariat. Uji statistik yang dipakai adalah uji Chi Square Test.

\section{HASIL DAN PEMBAHASAN}

\section{Analisis Univariat}

Tabel 1 Distribusi frekuensi Persepsi Masyarakat tentang JKN Mandiri di Puskesmas Perawatan Bakau tahun 2021

\begin{tabular}{lcc}
\hline \multicolumn{1}{c}{ Variabel } & $\mathrm{n}$ & $\%$ \\
\hline Kepesertaan JKN & & \\
Ya & 40 & 40,8 \\
Tidak & 58 & 59,2 \\
Persepsi Masyarakat & & \\
Positif & 64 & 65,3 \\
Negatif & 34 & 34,7 \\
Total & $\mathbf{9 8}$ & $\mathbf{1 0 0}$ \\
\hline
\end{tabular}

Berdasarkan tabel 1 menunjukkan bahwa sebagian besar responden tidak menjadi peserta JKN sebanyak 58 orang $(59,2 \%)$, persepsi masyarakat tentang JKN Mandiri yang positif sebanyak 64 orang $(65,3 \%)$. 


\section{Analisis Bivariat}

Tabel 2. Hubungan Persepsi Masyarakat tentang JKN dengan Kepesertaan Jaminan Kesehatan Nasional (JKN) Mandiri di Puskesmas Perawatan Bakau tahun 2021

\begin{tabular}{|c|c|c|c|c|c|c|c|}
\hline \multirow[t]{3}{*}{ Variabel } & \multicolumn{4}{|c|}{$\begin{array}{c}\text { Kepesertaan Jaminan Kesehatan Nasional } \\
\text { (JKN) }\end{array}$} & \multirow{3}{*}{$\begin{array}{c}\text { Jumlah } \\
\text { n }\end{array}$} & \multicolumn{2}{|c|}{$p$-value } \\
\hline & \multicolumn{2}{|c|}{ Ya } & \multicolumn{2}{|c|}{ Tidak } & & & \\
\hline & $\mathbf{n}$ & $\%$ & $\mathbf{N}$ & $\%$ & & $\%$ & \\
\hline \multicolumn{8}{|l|}{ Persepsi } \\
\hline Positif & 39 & 60,9 & 25 & 39,1 & 64 & 100 & 0,000 \\
\hline Negatif & 1 & 2,9 & 33 & 97,1 & 34 & 100 & \\
\hline Total & 40 & 40,8 & 58 & 59,2 & 98 & 100 & \\
\hline
\end{tabular}

\section{PEMBAHASAN}

\section{Kepesertaan JKN Mandiri di Wilayah Kerja Puskesmas Perawatan Bakau Tahun 2021}

Berdasarkan tabel 2 diketahui bahwa dari responden yang memiliki persepsi positif sebagian besar menjadi peserta JKN mandiri sebanyak 39 orang $(60,9 \%)$, sedangkan dari 34 responden yang memiliki persepsi negatif sebagian besar tidak menjadi peserta JKN mandiri sebanyak 33 orang $(97,1 \%)$. Hasil uji statistik dengan uji Chi Square di dapatkan $p$-value $=0,000<$ a 0,05 maka Ho di tolak artinya ada hubungan yang signifikan persepsi masyarakat dengan kepesertaan JKN Mandiri di Wilayah Kerja Puskesmas Perawatan Bakau Tahun 2021. Berdasarkan hasil penelitian menunjukkan bahwa sebagian besar responden tidak menjadi peserta JKN mandiri sebanyak 58 orang $(59,2 \%)$. Berdasarkan wawancara alasan responden yang belum menjadi peserta JKN karena pekerjaan tidak tetap dan penghasilan responden yang masih rendah sehingga responden beranggapan tidak dapat membayar iuran setiap bulannya jika ikut JKN mandiri, kurangnya informasi tentang JKN mandiri dikarenakan sebagian besar memiliki pendidikan dasar, memiliki persepsi yang masih negatif beranggapan bahwa menjadi peserta bukan suatu kewajiban serta tidak ada dukungan dari keluarga untuk ikutserta dalam program JKN mandiri padahal menjadi peserta JKN merupakan suatu kewajiban dari pemerintah agar pencapaian universal health coverage dan derajat kesehatan masyarakat.

Hasil wawancara dengan responden sebagian besar responden apabila sakit sebagian besar membeli obat diwarung sehingga beranggapan tidak perlu kefasilitas kesehatan hal ini yang dapat menyebabkan responden tidak berminat menjadi peserta JKN karena beranggapan salah padahal jika menjadi peserta JKN obat-obatan sebagian besar ditanggung oleh program JKN. Selain itu sebagian responden yang tidak menjadi peserta JKN dikarenakan beranggapan bahwa administrasi pelayanan program JKN ribet sehingga memilih menjadi peserta umum. Untuk meningkatkan antusias masyarakat menjadi peserta JKN mandiri dengan pihak puskesmas meningkatkan pelayanan seperti tidak ribet, tidak antri dan waktu pelayanan yang cepat. Menurut Niha (2018) Partisipasi masyarakat dalam program JKN diwujudkan dengan ikut serta dengan menjadi peserta JKN (3). Program JKN bertujuan untuk meningkatkan pencapaian universal health coverage dan derajat kesehatan masyarakat. Hal ini dapat tercapai apabila semua masyarakat mendaftarkan diri menjadi peserta JKN,. Akan tetapi, ada beberapa faktor yang dimungkinkan dapat mempengaruhi masyarakat untuk mendaftarkan diri sebagai peserta JKN yaitu pekerjaan, pendidikan, pengetahuan, sikap, penghasilan, jumlah anggota keluarga, persepsi, informasi dan dukungan keluarga (4). Hasil penelitian ini sejalan dengan penelitian Kusumaningrum (2018) menunjukkan bahwa responden yang menjadi peserta JKN sebanyak 40 orang $(40,0 \%)$ sedangkan yang tidak menjadi peserta (5)

\section{Persepsi masyarakat di Wilayah Kerja Puskesmas Perawatan Bakau Tahun 2021}

Berdasarkan hasil penelitian menunjukkan sebagian besar responden memiliki persepsi tentang JKN positif sebanyak 64 orang (65,3\%). Persepsi responden sebagian besar positf karena responden 
sudah memandang positif tentang program JKN yang dapat memberikan kemudahan dan keuntungan untuk responden. Namun masih ada responden yang memiliki persepsi negatif dikarenakan masih banyak responden yang beranggapan bahwa program JKN menjadi beban ketika ada yang sakit dan tidak mendapat kemudahan pelayanan kesehatan serta pendaftaran menjadi peserta JKN sangatlah dipersulit.

Lingkungan adalah segala jalinan kehidupan yang saling berhubungan satu sama lain. Lingkungan dalam penelitian ini mengenai faktor keluarga, teman, dan tetangga yang ikutserta dalam program, kondisi lingkungan sekitar yang merasa terbantu dengan adanya program JKN sehingga mempengaruhi persepsi masyarakat terhadap keikutsertaan JKN (6)

Menurut Kurniawan (2017) Masyarakat yang memiliki persepsi baik lebih banyak menjadi peserta JKN karena menilai bahwa JKN mampu membiayai pembiayaan kesehatannya dengan iuran yang cukup terjangkau bagi masyarakat (5). Hasil penelitian ini sejalan dengan penelitian Ernawati (2019) menunjukkan bahwa sebagian besar persepsi masyarakat tentang JKN positif sebanyak 37 orang $(41,4 \%)(7)$.

\section{Hubungan Persepsi Masyarakat dengan Kepesertaan JKN Mandiri di Wilayah Kerja Puskesmas Perawatan Bakau Tahun 2021}

Berdasarkan hasil penelitian menunjukkan dari 64 responden yang memiliki persepsi positif sebagian besar menjadi peserta JKN mandiri sebanyak 39 orang $(60,9 \%)$, sedangkan dari 34 responden yang memiliki persepsi negatif sebagian besar tidak menjadi peserta JKN mandiri sebanyak 33 orang $(97,1 \%)$. Hasil uji statistik dengan uji Chi Square di dapatkan p-value $=0,000<\alpha$ 0,05 maka Ho di tolak artinya ada hubungan yang signifikan persepsi dengan kepesertaan JKN Mandiri di Wilayah Kerja Puskesmas Perawatan Bakau Tahun 2021.

Persepsi masyarakat dengan kepesertaan JKN mandiri merupakan hubungan sebab akibat dikarenakan semakin positif persepsi responden tentang program JKN maka cenderung menjadi peserta JKN dibandingkan responden yang memiliki persepsi negatif tentang JKN cenderung tidak menjadi peserta JKN. Penelitian ini masih ada responden yang memiliki persepsi positif namun tidak menjadi peserta dikarenakan penghasilan responden yang masih rendah serta tidak ada dukungan dari keluarga. Namun pada penelitian ini juga ditemukan responden yang memiliki persepsi negatif namun ikut menjadi peserta JKN dikarenakan keluarga memberikan dukungan seperti informasi bahwa wajib menjadi peserta JKN dan manfaat yang diberikan jika menjadi peserta JKN (8).

Hasil penelitian menunjukkan bahwa sebagian besar responden memiliki persepsi positif tentang program JKN dikarenakan sudah banyak menjawab setuju pada pertanyaan yang bersifat positif yaitu nomor 1 sebanyak 50 orang (51,0\%) menjawab setuju bahwa program JKN mengurangi beban responden dan keluarga ketika ada yang sakit, pertanyaan nomor 6 sebanyak 53 orang $(54,1 \%)$ menjawab setuju bahwa semangat budaya gotong royong dan tolong menolong pada sistem JKN membuat JKN baik, dan pertanyaan nomor 9 sebanyak 52 orang $(53,1 \%)$ menjawab setuju bahwa orang-orang yang berada di Lingkungan sekitar saya merasa terbantu dengan adanya program JKN. Namun pada penelitian ini masih ada responden yang memiliki persepsi negatif tentang program JKN dikarenakan menjawab setuju pada pertanyaan yang bersifat negatif pada pertanyaan nomor 2 sebanyak 27 orang $(27,6 \%)$ menyatakan dengan menjadi peserta JKN saya tidak mendapat kemudahan pelayanan kesehatan dan pertanyaan nomor 5 sebanyak 33 orang $(33,7 \%)$ menyatakan biaya premi JKN memberatkan dan tidak sesuai kemampuan

Persepsi tentang JKN sangat penting dikarenakan dengan persepsi yang baik maka pandangan masyarakat tentang program JKN akan mendorong masyarakat untuk ikutserta dalam program JKN. Menurut Kusumaningrum (2018) persepsi masyarakat merupakan salah satu faktor yang berhubungan dengan kepesertaan masyarakat dalam JKN. Banyak keuntungan yang dirasakan dalam asuransi kesehatan oleh peserta maupun bukan peserta, seperti menawarkan perlindungan finansial kepada peserta, membuat peserta merasa nyaman saat keluarga mereka berada di rumah sakit, dan membangun solidaritas untuk membantu anggota masyarakat lainnya. Persepsi secara signifikan mempengaruhi keputusan untuk 
mendaftar dan tetap menjadi peserta asuransi kesehatan nasional (8).

Hasil penelitian ini sejalan dengan penelitian Kusumaningrum (2018) menunjukkan bahwa ada hubungan persepsi masyarakat dengan berhubungan dengan kepesertaan JKN secara mandiri dengan pvalue $=0,010$ (8). Penelitian ini sejalan dengan penelitian Ernawati (2019) menunjukkan bahwa ada hubungan persepsi masyarakat tentang JKN dengan Kepesertaan JKN Mandiri dengan p-value=0,010 (7).

Peserta mandiri merespon positif kenaikan iuran karena mereka mengetahui tujuan dari kenaikan iuran yaitu untuk mengatasi defisit dan peningkatan kualitas pelayanan. Hal tersebut juga didukung oleh manfaat yang dirasakan dari menggunakan JKN-KIS. Oleh karena itu, penting bagi BPJS Kesehatan untuk memberikan pelayanan yang maksimal kepada peserta agar mereka merasakan keuntungan dari penggunaan JKN-KIS yang kemudian akan menimbulkan persepsi yang baik dari peserta (10).

\section{KESIMPULAN DAN SARAN}

Dari hasil penelitian dan pembahasan maka dapat ditarik kesimpulan bahwa sebagian besar responden tidak menjadi peserta JKN mandiri sebanyak 58 orang $(59,2 \%)$ di Puskesmas Perawatan Bakau tahun 2021. Sebagian besar memiliki persepsi positif sebanyak 64 orang $(65,3 \%)$ di Puskesmas Perawatan Bakau Kabupaten Kotabaru tahun 2021. Ada hubungan persepsi tentang JKN dengan kepesertaan JKN mandiri di Puskesmas Perawatan Bakau Kabupaten Kotabaru tahun 2021 ( $p$ value $=0,000$ ). Saran kepada petugas kesehatan diharapkan dapat mengoptimalkan penyuluhan kepada masyarakat tentang pentingnya ikut dalam program JKN dengan menggunakan spanduk, leaflet, brosur, melewati tokoh masyarakat minimal 1 bulan sekali.

\section{DAFTAR PUSTAKA}

1. Syah R, Muh Al Thakhrik, Abadi, Muh Yusri dan Palutturi Sukri . 2016. Hubungan Persepsi Masyarakat Tentang Jkn Terhadap Keikutsertaan Menjadi Peserta Bpjs Kesehatan Di Wilayah Puskesmas Minasa Upa. Fakultas Kesehatan Masyarakat, Universitas Hasanuddin.
2. Witcahyo, Eri. 2016. Kesiapan dan Persepsi Masyarakat Kabupaten Bondowoso terhadap Kebijakan Jaminan Kesehatan Nasional (JKN). Jember : Jurnal Kesehatan Masyarakat Universitas Jember.

3. Niha, Munawir Rizal, 2018. Hubungan Karakteristik Individu Dan Pengetahuan Tentang Jaminan Kesehatan Nasional-Kartu Indonesia Sehat (JKN-KIS) Dengan Status Kepesertaan Masyarakat Dalam Program Jknkis Di Kecamatan Singkil Kota Manado. Universitas Sam Ratulangi.Vol.7 No.5.

4. Kurniawan, 2017. Faktor Faktor Yang Mempengaruhi Masyarakat Dalam Pemanfaatan Jaminan Kesehatan Nasional Di Wilayah Kerja Puskesmas Tamalanrea Jaya Kota Makassar. Departemen Administrasi Dan Kebijakan Kesehatan Fakultas Kesehatan Masyarakat Universitas Hasanuddin Makassar. Skripsi.

5. Kusumaningrum, A. 2018. Kepesertaan Masyarakat dalam Jaminan Kesehatan Nasional secara Mandiri. HIGEIA (Journal of Public Health Research and Development), 2(1), 149-160.

6. Rumengan, Debra.2015. Faktor-faktor yang Berhubungan dengan Pemanfaatan Pelayanan Kesehatan Pada Peserta BPJS Kesehatan di Puskesmas Paniki Bawah Kecamatan Mapanget Kota Manado. Manado: Jurnal Kesehatan Masyarakat Universitas Sam Ratulangi Manado.

7. Ernawati, 2019. Hubungan Kepesertaan JKN Mandiri Dengan Pendapatan, Pengetahuan, Persepsi, Akses, Dan Kepercayaan Masyakat Suku Sakai Di Desa Petani Kecamatan Mandau Kabupaten Bengkalis Tahun 2018. Fakultas Kesehatan Masyarakat Universitas Andalas. Vol.8 No.1 (2019)

8. Nadiyah, Husnun, 2017. Faktor-Faktor Yang Berhubungan Dengan Kepesertaan Program JKN Di Wilayah Kerja Puskesmas Remaja Kota Samarinda. Fakultas Kesehatan Masyarakat Universitas Mulawarman Samarinda. Vol.6 No.2 (2017)

9. Kusumaningrum, A. 2018. Kepesertaan Masyarakat dalam Jaminan Kesehatan Nasional secara Mandiri. HIGEIA (Journal of Public Health Research and Development), 2(1), 149-160.

10. Arifin HS, Fuady I, Kuswarno E. Analisis Faktor yang Mempengaruhi Persepsi Mahasiswa terhadap Keberadaan Perda Syariah di Kota Serang. J Penelit Komonikasi dan Opini Publik. 2017;21(1):88-101. 